\title{
Acesso à Justiça Durante a Pandemia da Covid-19: o caso do estado do Paraná
}

\author{
Juliane Milani² \\ Alexandre dos Santos Cunha ${ }^{3}$
}

\section{INTRODUÇÃO}

No final de 2019, o mundo foi surpreendido pelo surgimento da Covid-19, cujo alto grau de disseminação levou à declaração de situação de pandemia por parte da Organização Mundial da Saúde (OMS) (Moreira e Pinheiro, 2020). No Brasil, os primeiros casos foram relatados no final de fevereiro de $2020 .^{4}$

Diante desse cenário, adotando-se o recorte territorial do estado do Paraná, este estudo tem como objetivo analisar como têm funcionado os serviços de assistência judiciária gratuita durante o período da pandemia. Para tanto, com base em pesquisa bibliográfica, inicialmente aborda-se de maneira breve as instituiçóes de acesso à justiça no estado do Paraná e como elas atuam para promover esse acesso. Na sequência, a partir de pesquisa empírica de tipo exploratório, faz-se uma análise dos desafios impostos a essas instituiçóes e como elas se organizaram para atuar nesse contexto.

\section{INSTITUIÇ̃̃ES DE ACESSO À JUSTIÇA NO ESTADO DO PARANÁ}

No Brasil, o acesso à justiça é reconhecido como um direito fundamental e se encontra inscrito no art. 5o, inciso XXXV, da Constituição Federal de 1988 (CF/1988). No entanto, embora o direito de acesso à justiça tenha sua importância reconhecida, muitos ainda vivem à margem dessa proteção, não tendo suas necessidades ou problemas jurídicos amparados de forma eficiente (Lauris, 2009). Nesse sentido, nos termos do art. 134 da CF/1988, é a Defensoria Pública que, exercendo função essencial à justiça, encontra-se encarregada da prestação de assistência jurídica integral e gratuita a todos aqueles que comprovarem a insuficiência de recursos.

A Defensoria Pública da União (DPU) foi organizada pela Lei Complementar nº 80/1994 e atualmente conta com 467 defensores que atuam na primeira instância, 122 que atuam nos tribunais regionais, e cinquenta, nos tribunais superiores. ${ }^{5}$ No estado do Paraná, ela está presente nas circunscriçôes judiciárias federais de Curitiba, Cascavel, Foz do Iguaçu e Londrina, atendendo cidadãos com renda familiar inferior a $\mathrm{R} \$ 2.000,00 .^{6}$

A Defensoria Pública do Estado do Paraná, por sua vez, só veio a ser efetivamente instituída em 2011, com a Lei Estadual oㅜ 136/2011. Atualmente, conta 109 defensores públicos ativos, ${ }^{7}$ que estâo divididos em apenas dezoito das 161 comarcas existentes no estado. ${ }^{8}$ Os critérios para atendimento pela

1. DOI: http://dx.doi.org/10.38116/bapi25art10

2. Advogada; mestranda em direito na Universidade Positivo.

3. Técnico de planejamento e pesquisa na Diretoria de Estudos e Políticas do Estado, das Instituições e da Democracia (Diest) do Ipea.

4. Disponível em: <https://coronavirus.saude.gov.br/linha-do-tempo/>.

5. Disponível em: <https://bit.ly/3pV9QDE>. Acesso em: 5 nov. 2020.

6. Disponível em: <https://bit.ly/3nvT2kV>. Acesso em: 5 nov. 2020.

7. Disponível em: <https://bit.ly/3os72gR>. Acesso em: 30 maio 2020.

8. Disponível em: <https://bit.ly/35jbuHm>. Acesso em: 3 nov. 2020. 
defensoria do Paraná, estabelecidos pela Deliberação no 42/2017 do Conselho Superior da Defensoria Pública, são: i) renda mensal familiar de três salários mínimos; ii) não possuir direitos, bens móveis ou imóveis que ultrapassem 1.500 unidades fiscais do Paraná; iii) não possuir recursos financeiros por meio de investimentos ou aplicaçóes que excedam doze salários mínimos. Entretanto, em que pese a estrutura bem definida do órgão e seu importante papel assumido ao longo dos anos na promoção do acesso à justiça à população vulnerável, a sua atuação ainda está muito aquém do necessário.

De acordo com o Mapa das Defensorias Públicas Estaduais no Brasil, em seu segundo volume, ainda no prelo, realizado pelo Ipea e pela Associação Nacional das Defensoras e Defensores Públicos (ANADEP), em 2019 o Paraná possuía a pior média do país em quantidade de defensores estaduais, ao se levar em conta a população do estado com renda até três salários mínimos. Estimou-se que a porcentagem de defensores para cada 10 mil habitantes com baixa renda equivalia a 0,12 , apresentando um deficit de 743 defensores públicos. Segundo o estudo, o recomendável seria a existência um defensor para cada 10 mil ou 15 mil habitantes de baixa renda.

Assim, diante da evidente impossibilidade da Defensoria Pública do Estado do Paraná em atender toda a demanda da população vulnerável, a atuação de outras instituições que promovam o acesso à justiça se revela necessária. Para tanto, destaca-se o papel desenvolvido pelos Núcleos de Prática Jurídica (NPJs) das instituiçóes de ensino superior de direito que, visando ao aprimoramento profissional dos acadêmicos, atuam casuisticamente no atendimento à populaçáo vulnerável e contribuem para o exercício da cidadania e a promoçáo da justiça social aos atendidos (Vercelli, 2014).

Embora houvessem experiências anteriores, os NPJs passaram a ser uma exigência a partir da edição da Portaria no 1.886/1994, do Ministério da Educaçáo (MEC), que fixava as diretrizes curriculares e o conteúdo mínimo para os cursos de direito. Atualmente, essas diretrizes encontram-se reguladas pela Resolução no 5/2018, que estabelece a obrigatoriedade da existência, em todas as instituiçóes de ensino de direito, de um NPJ.

De acordo com o Cadastro Nacional de Cursos e Instituições de Educação Superior do e-MEC, no Paraná existem 123 cursos de direito ativos, divididos entre cem instituiçóes. Após pesquisas via rede mundial de computadores e também por meio de contato telefônico, apesar da obrigatoriedade legal, constatou-se que apenas 83 dessas instituiçóes possuem NPJs, que estão distribuídos em 35 municípios. ${ }^{10}$ Os critérios e as áreas atendidas variam entre cada um dos núcleos, sendo mais comum o atendimento nas áreas de direito de família e criminal.

\section{DESAFIOS IMPOSTOS PELA PANDEMIA ÀS INSTITUIÇÕES DE ACESSO À JUSTIÇA NO ESTADO DO PARANÁ}

\subsection{Medidas de enfrentamento da Covid-19}

Antes de abordar especificamente a temática dos desafios impostos pela pandemia ao acesso à justiça no Paraná, deve-se fazer um breve retrospecto do avanço do vírus e das medidas de enfrentamento adotadas no estado, especialmente pelas instituiçóes objeto deste estudo.

9. Disponível em: <http://emec.mec.gov.br/>.

10. São eles: Apucarana, Araucária, Cambé, Campo Largo, Campo Mourão, Cascavel, Cornélio Procópio, Curitiba, Dois Vizinhos, Foz do Iguaçu, Francisco Beltrão, Guarapuava, Guaratuba, Ibaiti, Ivaiporã, Jacarezinho, Jaguariaíva, Londrina, Mandaguari, Marechal Cândido Rondon, Maringá, Medianeira, Paranaguá, Paranavaí, Pato Branco, Pinhais, Pitanga, Ponta Grossa, Rolândia, Santo Antônio da Platina, São José dos Pinhais, Telêmaco Borba, Toledo, Umuarama e União da Vitória. 
O primeiro caso provável do novo coronavírus no estado do Paraná se deu em 11 de março de 2020. Em 23 de março, por meio do Decreto no 4.319/2020, o governo do Paraná declarou estado de calamidade pública. Mesmo antes deste decreto, no entanto, algumas medidas para contenção da disseminação da Covid-19 já vinham sendo tomadas. A exemplo disso, cita-se o Decreto no 4.230 , de 16 de março de 2020, do estado do Paraná, que determinou a suspensão das aulas em escolas estaduais, públicas e privadas e em universidades públicas a partir do dia 20 de março de 2020. Seguindo essa mesma linha, as universidades particulares também aderiram à suspensão das aulas. Consequentemente, as atividades desempenhadas pelos NPJs dessas instituiçóes, ao menos nesse momento, acabaram sendo igualmente suspensas.

No âmbito do Tribunal de Justiça do Estado do Paraná (TJPR), foi publicado o Decreto Judiciário no 161/2020, que suspendeu as atividades presenciais por catorze dias e ainda autorizou a realização do teletrabalho. Esse decreto foi revogado pelo Decreto Judiciário no $172 / 2020$, que previu a suspensão dos prazos processuais até 30 de abril e a manutenção do regime de teletrabalho, que, por força do atual Decreto Judiciário no 343/2020, continua mantido. Até a data de conclusão deste artigo, as atividades presenciais do TJPR continuavam suspensas, mas os prazos processuais e os processos tramitavam normalmente.

A Defensoria Pública do Estado do Paraná, por seu turno, editou em 23 de março de 2020 a Resoluçáo no 88 , que dispôs sobre a prevençáo à pandemia da Covid-19 e regulamentou o trabalho remoto. Desde então, e até a data da conclusão deste estudo, não houve mais atendimento presencial por parte desse órgão, mantendo-se a prestação dos serviços apenas por celular, WhatsApp e e-mail. A DPU também suspendeu os atendimentos presenciais e tem atuado em esquema de plantáo telefônico.

\subsection{Atendimento durante a pandemia}

O objetivo deste artigo é analisar, entre as instituições de acesso à justiça identificadas, como tem sido sua prestação de serviços jurídicos gratuitos e quais desafios elas têm enfrentado durante a pandemia da Covid-19. Para tanto, foi feita uma pesquisa por meio da rede mundial de computadores junto ao sítio eletrônico de cada uma das instituiçôes, assim como foi feito contato telefônico com todas elas.

Em relaçáo à DPU, a análise centra-se na questáo do auxílio emergencial, por se tratar de benefício criado justamente para atender às necessidades de renda da população vulnerável durante o período da pandemia, e por ter se tornado foco de atenção prioritária da organização. Na página inicial do sítio eletrônico do órgão, consta um banner com informações referentes à sua atuação no enfrentamento às consequências da pandemia do novo coronavírus. Ao clicar no banner, o usuário é redirecionado para uma página com várias outras informações e opções. Uma dessas opções é a de Acordo DPU e Ministério da Cidadania, na qual o usuário é informado de que náo deve comparecer presencialmente à unidade da defensoria, pois os atendimentos estáo sendo feitos de maneira remota, devendo acessar o link disponibilizado para localizar os contatos da unidade da DPU que atenda à sua cidade. Ao clicar no referido link e selecionar o estado do Paraná, o usuário terá à sua disposição os contatos para cada uma das cinco unidades de atendimento.

Com relação à circunscrição judiciária federal de Curitiba, além dos telefones para contato, consta a informação de que o atendimento para auxílio emergencial está sendo feito somente mediante formulário disponível no próprio site, o qual deve ser preenchido pelo usuário para posterior contato pela DPU. Além disso, o atendimento foi limitado ao número máximo diário de cinquenta 
formulários. Ao entrar em contato pelo telefone fixo da DPU no dia 4 de novembro de 2020, as informaçóes prestadas foram as mesmas. Na unidade de Cascavel, foi repassada a informação de que todos os atendimentos relacionados ao auxílio emergencial são feitos exclusivamente por meio do WhatsApp, pelo qual o usuário envia a solicitação e aguarda assistência.

Em Foz do Iguaçu, por sua vez, as tentativas de contato pelo telefone fixo foram infrutíferas. Em função disso, enviou-se mensagem por meio do aplicativo WhatsApp ao telefone do plantão, recebendo-se uma resposta automática, com mensagem padrão informando que o atendimento estava sendo realizado exclusivamente por meio de determinado endereço de e-mail.

Em Londrina, também não houve atendimento pelo telefone fixo, apenas por meio do WhatsApp do plantão, no qual foi informado que não serão atendidas novas demandas relativas ao auxílio emergencial, ao menos até o final do ano, sendo que aqueles que precisarem de atendimento deverão procurar o Setor de Atermaçáo da Justiça Federal em Londrina.

Por fim, na unidade de Umuarama, o telefone fixo foi atendido pelo vigilante, que informou que os contatos estão sendo feitos apenas pelo WhatsApp do plantão. Após o envio de mensagem, o usuário deve informar seus dados e aguardar que a DPU entre em contato.

A Defensoria Pública do Estado do Paraná também divulgou em seu sítio eletrônico um alerta $^{11}$ sobre o atendimento durante a pandemia do coronavírus. Ao clicar nessa mensagem, o usuário é redirecionado a uma página em que constam os contatos da sede central e das comarcas em que há atuação. Ao lado de cada local de atendimento consta o número de contato com a opção de envio de mensagens via aplicativo WhatsApp, podendo o usuário apenas clicar no número e ser direcionado a uma conversa particular. Em algumas sedes, o usuário pode ainda selecionar o número de telefone correspondente ao primeiro atendimento ou apenas ao acompanhamento processual, a fim de facilitar o contato.

As informaçôes sobre cada uma das sedes, tais como dias específicos de atendimento, horário de funcionamento e e-mail para contato, podem ser encontradas clicando diretamente no nome da respectiva sede. Na sede central de atendimento, por exemplo, a grande maioria dos serviços está disponível de segunda-feira a quinta-feira, das $13 \mathrm{~h}$ às $17 \mathrm{~h}$, com exceção daqueles em que há distribuição de senhas, como é o caso do atendimento inicial na área de direito de família, o qual só está disponível até que sejam distribuídas as vinte senhas diárias. Após essa distribuição, a pessoa já náo consegue contato por meio do envio de mensagens via WhatsApp, recebendo uma mensagem automática que informa que o horário de atendimento foi encerrado ou que as senhas não estão mais disponíveis, devendo retornar o contato no dia seguinte.

No entanto, apesar de ter havido preocupação por parte da Defensoria Pública do Estado do Paraná em disponibilizar formas de atendimento em seu sítio eletrônico, deve-se ressaltar que, de acordo com a Pesquisa Nacional por Amostra de Domicílios Contínua (Pnad Contínua) sobre o tema suplementar Tecnologia da Informação e Comunicação (TIC), de 2018, ${ }^{12}$ 19,5\% da população paranaense não possui acesso à internet, o que pode dificultar o acesso aos órgãos por parte desses indivíduos (IBGE, 2018). Isso porque, ao entrar em contato com os telefones fixos da defensoria do Paraná, normalmente disponibilizados à população, por exemplo, não há qualquer tipo de

11. Disponível em: <http://www.defensoriapublica.pr.def.br/>. Acesso em: 11 ago. 2020.

12. A Pnad Contínua TIC de 2018 foi divulgada no dia 29 de abril de 2020 e apresenta dados referentes ao último trimestre de 2018. De acordo com os dados divulgados, apenas $80,5 \%$ da população paranaense utilizava internet em suas residências naquele período (IBGE, 2018). 
atendimento ou gravação de mensagem que indique como o usuário deverá proceder. ${ }^{13} \mathrm{O}$ mesmo acontece com algumas unidades da DPU no Paraná, nas quais praticamente todos os atendimentos dependem de acesso à internet.

No caso dos NPJs, deve-se ressaltar que, até a data de conclusão deste artigo, todas as instituiçóes, tanto públicas como privadas, de ensino superior do estado do Paraná em que há NPJs com atendimento à população estavam com aulas presenciais suspensas. Algumas encontravam-se em regime de teletrabalho, outras apenas com expediente interno, e outras prestando apenas determinados serviços à comunidade. Como dito, foram identificadas 83 dessas instituiçóes no estado em que há prestação de serviços jurídicos gratuitos à comunidade. Contudo, infelizmente as informaçóes acerca do funcionamento desses NPJs durante a pandemia não estáo disponíveis nos seus respectivos sítios eletrônicos. Aliás, em alguns casos não é possível sequer encontrar um número telefônico para contato direto com os respectivos núcleos.

A fim de identificar quais NPJs estavam prestando atendimento à população durante o período da pandemia, especialmente no que se refere a novas demandas, entrou-se em contato telefônico com todas as 83 instituiçóes, entre os dias 11 de agosto e 9 de setembro de 2020. Por meio desses contatos, verificou-se que onze NPJs estão funcionando normalmente, prestando atendimento à população para novas demandas durante a pandemia de forma presencial. ${ }^{14}$ Seis NPJs estariam retomando suas atividades a partir de setembro. ${ }^{15} \mathrm{Um} \mathrm{NPJ}$ informou que retornou às suas atividades, mas que, no momento, somente realizava atendimento no que se refere ao auxílio emergencial. ${ }^{16}$ Oito NPJs, apesar de não estarem realizando atendimento presencial, informaram que estão prestando atendimento e orientaçóes remotamente, também para novos casos, por meio de telefone ou e-mail, a fim de tentar dar continuidade aos serviços. ${ }^{17}$

Com esse levantamento constatou-se, então, que apenas 26 dos 83 NPJs estão, de alguma forma, tentando manter a provisão de novos serviços jurídicos gratuitos à população, mesmo durante o período da pandemia.

\footnotetext{
13. Essas informações foram obtidas após a realização de teste com ligações para os números (41) 3219-7300 (atendimento central) e (41) 3313-7336 (sede administrativa) da Defensoria Pública do Estado do Paraná, em 12 agosto de 2020, por volta das 14h, e em 13 de agosto de 2020, por volta das 16h. As informações para atendimento durante a pandemia foram encontradas apenas na página oficial da defensoria. Disponível em: <https://bit.ly/2Ldqdgc>. Acesso em: 12 ago. 2020.

14. Trata-se dos NPJs das seguintes instituições: Universidade Norte do Paraná (Unopar); Faculdade de Direito Francisco Beltrão/Centro Sulamericano de Ensino Superior (Cesul); Centro Universitário Integrado de Campo Mourão; Universidade Paranaense (Unipar); Instituto Superior do Litoral do Paraná (Isulpar); Faculdade de Ensino Superior de Marechal Cândido Rondon (Isepe Rondon); Faculdade Educacional de Araucária (Unifacear); Faculdade Nacional de Educação e Ensino Superior do Paraná (Faneesp); Faculdade Integradas do Vale do Iguaçu (Uniguaçu); Faculdades Integradas do Vale do Ivaí (Univale); e Centro Universitário da União de Ensino do Sudoeste do Paraná (Unisep), campus de Dois Vizinhos. 15. Trata-se dos NPJs das seguintes instituições: Centro Universitário Curitiba (UNICURITIBA); Centro Universitário de Maringá (UniCesumar); Universidade Estadual do Norte do Paraná (UENP); Centro Universitário de Cascavel (Univel); Faculdade Assis Gurgacz (FAG Toledo); e Faculdade Guarapuava (FG).

16. Trata-se do NPJ da Faculdade de Apucarana (FAP).

17. Trata-se dos NPJs das seguintes instituições: Pontifícia Universidade Católica do Paraná (PUCPR); Universidade Positivo (UP); Complexo de Ensino Superior Arthur Thomas (CESA); Faculdade da Indústria São José dos Pinhais (FAIND/SJP); Faculdade Paranaense (FAPAR); Faculdade Santa Amélia (Sociedade Educativa e Cultural Amélia - SECAL); Faculdade Santa Maria da Glória (SMG); e Faculdade de Ensino Superior do Centro do Paraná (UCP).
} 


\section{GRÁFICO 1}

\section{Atendimento nos NPJs durante a pandemia da Covid-19}

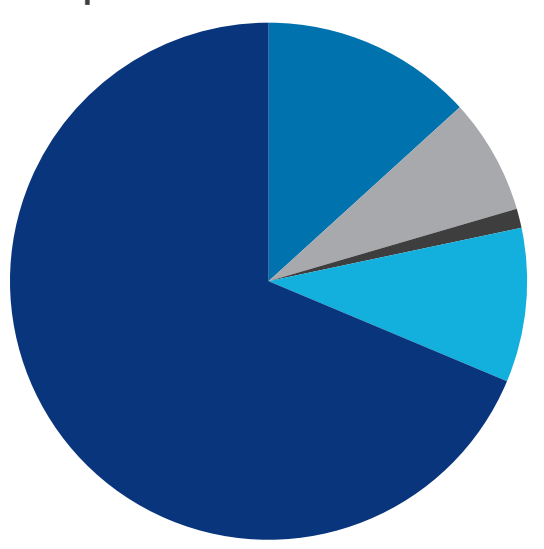

- Sem nenhum atendimento

Atendimento presencial

Retomada em setembro

Elaboração dos autores.

Aqueles que não estão conseguindo ofertar os serviços jurídicos à comunidade informaram que suas dificuldades são basicamente duas. A primeira se dá com relaçáo ao fato de que as aulas presenciais estão suspensas e, em razão disso, os alunos, que são os principais responsáveis pelos atendimentos e pela elaboração das peças processuais, não estão comparecendo. A segunda dificuldade, segundo informaçóes fornecidas pelas próprias instituiçóes, é de que os decretos municipais ainda não permitem a abertura deste tipo de estabelecimento.

\section{CONCLUSÃO}

Dado o exposto neste estudo, percebe-se que, diante da crise sanitária ocasionada pela Covid-19, apenas algumas das instituiçóes voltadas à promoção do acesso à justiça no estado do Paraná têm buscado formas de manter a prestação dos seus serviços, no intuito de assegurar serviços jurídicos gratuitos àqueles que necessitam.

No caso das defensorias públicas da União e do estado do Paraná, constatou-se que houve empenho por parte dos órgãos na criação de uma sistemática para atendimento aos interessados por meio de telefone, e-mail ou também pelo aplicativo WhatsApp. Pode-se dizer, contudo, que a defensoria pública tem cumprido apenas parcialmente sua função constitucional, pois, apesar de oferecer meios de atendimento, estes são ofertados quase exclusivamente por meio da internet, de modo que aqueles que não possuem acesso à rede mundial de computadores terão dificuldades para entrar em contato com o órgão e ter suas necessidades atendidas, já que em alguns telefones fixos da instituição não há qualquer atendimento ou indicação de como o assistido deverá proceder.

Com relação aos NPJs do estado do Paraná, pode-se afirmar que, apesar de ocuparem papel relevante como instituiçóes na promoção do acesso à justiça, boa parte não tem cumprido com seu compromisso de prestação de serviços jurídicos gratuitos à população vulnerável durante o período da pandemia, pois somente 26 NPJs estão ofertando seus serviços de alguma forma. 


\section{REFERÊNCIAS}

BRASIL. Constituição da República Federativa do Brasil de 1988. Diário Oficial da Uniáo, Brasília, 5 out. 1988. Disponível em: <http://www.planalto.gov.br/ccivil_03/constituicao/constituicao.htm>.

. Lei Complementar no 80, de 12 de janeiro de 1994. Organiza a Defensoria Pública da União, do Distrito Federal e dos territórios e prescreve normas gerais para sua organização nos estados, e dá outras providências. Diário Oficial da Uniáo, Brasília, 13 jan. 1994. Disponível em: <http://www.planalto.gov.br/ccivil_03/leis/LCP/Lcp80.htm>.

Portaria no 1.886 , de 30 de dezembro de 1994. Fixa as diretrizes curriculares e o conteúdo mínimo do curso jurídico. [s.l.]: [s.n.], 1994. Disponível em: <https://www.migalhas.com.br/ arquivo_artigo/art20100108-03.pdf>.

Resolução nº 5, de 17 de dezembro de 2018. Institui as diretrizes curriculares nacionais do curso de graduação em direito e dá outras providências. Diário Oficial da Uniáo, Brasília, p. 122, 18 dez. 2018. Seção 1. Disponível em: <https://bit.ly/3s5yuU0>.

CAPPELLETTI, Mauro; GARTH, Bryant. Acesso à justiça. Tradução de Ellen Grancie Northfleet. Porto Alegre: Fabris, 1988.

IBGE - INSTITUTO BRASILEIRO DE GEOGRAFIA E ESTATÍSTICA. Acesso à internet e à televisáo e posse de telefone móvel celular para uso pessoal: PNAD Contínua 2018 - análise dos resultados. [s.1.]: IBGE, 2018. Disponível em: <https://bit.ly/2MaC0ML>.

IPEA - INSTITUTO DE PESQUISA ECONÔMICA APLICADA; ANADEP - ASSOCIAÇÃO NACIONAL DAS DEFENSORAS E DEFENSORES PÚBLICOS. Mapa das defensorias públicas estaduais no Brasil: base de dados das comarcas. Rio de Janeiro: Ipea; ANADEP, 2019. v. 2.

LAURIS, Élida. Entre o social e o político: a luta pela definição do modelo de acesso à justiça em São Paulo. Revista Crítica de Ciências Sociais, n. 87, p. 121-142, 2009. Disponível em: <http:// journals.openedition.org/rccs/1464>.

MOREIRA, Ardilhes; PINHEIRO, Lara. OMS declara pandemia de coronavírus. G1, 11 mar. 2020. Disponível em: <https://glo.bo/3bhDsqR>.

PARANÁ. Conselho Superior da Defensoria Pública do Estado do Paraná. Deliberação CSDP no 042, de 15 de dezembro de 2017. Substitui a Deliberação CSDP no 19/2014 e dispóe sobre o atendimento de pessoas físicas pela Defensoria Pública do Estado do Paraná. Curitiba: DPPR, 2017. Disponível em: <http://www.defensoriapublica.pr.def.br/arquivos/File/Institucional/Conselho_Superior/ Deliberacoes_2017/DELIBERACAO_42.pdf>.

. Decreto no 4.230, de 16 de março de 2020. Dispóe sobre as medidas para enfrentamento da emergência de saúde pública de importância internacional decorrente do coronavírus - Covid-19. Diário Oficial, n. 10646, 16 mar. 2020. Disponível em: <https://bit.ly/3bkH23n>. Acesso em: 11 ago. 2020.

Decreto no 4.319, de 23 de março de 2020. Declara o estado de calamidade pública, como medida para enfrentamento da emergência de saúde pública de importância internacional decorrente do coronavírus - Covid-19. Diário Oficial, n. 10653, 23 mar. 2020. Disponível em: <https://bit. ly/3pYpqhZ>. 
- Defensoria Pública do Estado do Paraná. Resolução no 088, de 23 de março de 2020. Dispóe sobre a prevenção à pandemia da Covid-19 e regulamenta o trabalho remoto. [s.l.]: [s.n.]: 2020. Disponível em: <http://www.defensoriapublica.pr.def.br/arquivos/File/Legislacao/Resolucoes_ DPG/2020/Resolucao_088_.pdf>.

Tribunal de Justiça do Estado do Paraná. Decreto Judiciário no 161/2020. Dispóe sobre a prevenção ao coronavírus (Covid-19) no âmbito do Poder Judiciário do estado do Paraná. Curitiba: TJPR, 2020. Disponível em: <https://bit.ly/2Xn2ZGP>.

- Tribunal de Justiça do Estado do Paraná. Decreto Judiciário no 343/2020. Prorroga, no âmbito do Poder Judiciário do estado do Paraná, o regime de trabalho instituído pelo Decreto no 227/2020, alterado pelos decretos no 244/2020, no 262/2020 e no 303/2020. Curitiba: TJPR, 30 jun. 2020. Disponível em: <https://bit.ly/38rk5d7>.

VERCELLI, Ligia de Carvalho Abões. Espaço educativo não formal: o Núcleo de Prática Jurídica em pauta. Revista da Faculdade de Educação, ano 12, v. 21, n. 1, p. 67-82, jan./jun. 2014. Disponível em: <http://www2.unemat.br/revistafaed/content/vol/vol_21/artigo_21/67_82.pdf>. 